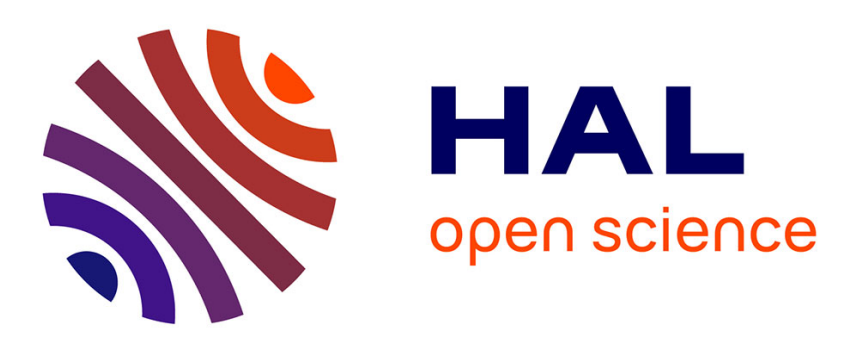

\title{
Extracellular matrix scaffolding in angiogenesis and capillary homeostasis
}

Marion Marchand, Catherine Monnot, Laurent Muller, Stéphane Germain

\section{To cite this version:}

Marion Marchand, Catherine Monnot, Laurent Muller, Stéphane Germain. Extracellular matrix scaffolding in angiogenesis and capillary homeostasis. Seminars in Cell and Developmental Biology, 2019, 89, pp.147-156. 10.1016/j.semcdb.2018.08.007 . hal-02163238

\section{HAL Id: hal-02163238 \\ https://hal.science/hal-02163238}

Submitted on 22 Oct 2021

HAL is a multi-disciplinary open access archive for the deposit and dissemination of scientific research documents, whether they are published or not. The documents may come from teaching and research institutions in France or abroad, or from public or private research centers.
L'archive ouverte pluridisciplinaire HAL, est destinée au dépôt et à la diffusion de documents scientifiques de niveau recherche, publiés ou non, émanant des établissements d'enseignement et de recherche français ou étrangers, des laboratoires publics ou privés.

\section{다)(1) $(5$}

Distributed under a Creative Commons Attribution - NonCommercial| 4.0 International 


\section{Extracellular matrix scaffolding in angiogenesis and capillary homeostasis}

Marion Marchand ${ }^{\mathrm{a}, \mathrm{b}}$, Catherine Monnot $^{\mathrm{a}}$, Laurent Muller ${ }^{\mathrm{a}}$, Stéphane Germain ${ }^{\mathrm{a}}$

${ }^{a}$ Center for Interdisciplinary Research in Biology (CIRB), College de France, CNRS, INSERM, PSL Research University, Paris, France

College de France

11 place Marcelin Berthelot, 75005 PARIS, France

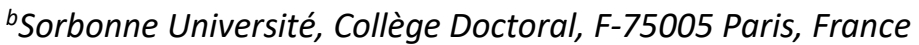

Corresponding author: Stéphane Germain stephane.germain@college-de-france.fr, Center for Interdisciplinary Research in Biology (CIRB), College de France, CNRS, INSERM, PSL Research University, College de France, 11 place Marcelin Berthelot, 75005 PARIS, France. tel +3314427 1664 ; fax +331 4427 1691 


\begin{abstract}
The extracellular matrix (ECM) of blood vessels, which is composed of both the vascular basement membrane (BM) and the interstitial ECM is identified as a crucial component of the vasculature. We here focus on the unique molecular composition and scaffolding of the capillary ECM, which provides structural support to blood vessels and regulates properties of endothelial cells and pericytes. The major components of the BM are collagen IV, laminins, heparan sulfate proteoglycans and nidogen and also associated proteins such as collagen XVIII and fibronectin. Their organization and scaffolding in the BM is required for proper capillary morphogenesis and maintenance of vascular homeostasis. The BM also regulates vascular mechanosensing. A better understanding of the mechanical and structural properties of the vascular BM and interstitial ECM therefore opens new perspectives to control physiological and pathological angiogenesis and vascular homeostasis. The overall aim of this review is to explain how ECM scaffolding influences angiogenesis and capillary integrity.
\end{abstract}

\title{
Keywords
}

Extracellular Matrix ; Basement Membrane ; Vascular Development ; Angiogenesis ; Capillary 
1. Introduction

2. Core components of the vascular basement membrane

2.1. Laminin

2.2. Collagen IV

2.2.1. Synthesis and secretion

2.2.2. Assembly in the BM

2.2.3. Cross-linking

2.3. Perlecan and nidogen

3. Extracellular matrix proteins associated to the vascular basement membrane

3.1. Collagens

3.1.1. Collagen XVIII

3.1.2. Collagen VIII

3.1.3. Collagen $\mathrm{VI}$

3.2. Fibronectin

3.2.1. Expression and fibrillogenesis

3.2.2. Assembly in the ECM

4. Basement membrane scaffolding and function in vascular development and homeostasis

4.1. Laminins

4.1.1. Laminin 411

4.1.2. Laminin 511

4.2. Collagen IV

4.3. Fibronectin

5. The extracellular matrix: a reservoir for growth factors and matricellular proteins

5.1. The VEGF family and its receptors

5.2. The PDGF family and its receptors

5.3. Matricellular proteins

5.3.1. Angiopoietins

5.3.2. CCN proteins

6. Concluding remarks

Acknowledgements

Fundings

References 


\section{Introduction}

The extracellular matrix (ECM) is a crucial component of the cellular microenvironment and forms a complex three-dimensional network. The vascular ECM is composed of two different compartments: the basement membrane (BM) and the interstitial ECM. Their respective ratio, composition and architecture differ depending on the nature (artery, vein, capillary) and the surrounding environment of the blood vessel. In the wall of large vessels, the interstitial ECM present in the media and embedding vascular smooth muscle cells displays the structural and mechanical properties that are necessary for supporting shear stress and pressure, i.e. high stiffness and elasticity. This interstitial ECM is thus mainly composed of elastic fibers and fibrillar collagens, collagen I being by far the most abundant protein in the wall of large vessels. It is crucial for establishing and maintaining the mechanical stability of the vascular system, as demonstrated in mice deficient for the $\alpha 1$ chain of collagen I, which die between E12 and E14 due to rupture of major blood vessels [1]. In capillaries, the vascular wall is limited to the BM. This specialized macromolecular assembly of proteins separates the endothelium from the surrounding stromal tissue [2]. It forms a continuous sheet-like structure of 50 to $150 \mathrm{~nm}$ thickness that surrounds the basal surface of the endothelial monolayer and ensheathes perivascular cells, which also participate to BM synthesis and organization [3, 4]. Since capillaries lack smooth muscle cells and the associated interstitial ECM, the BM alone provides the structural and mechanical features that support the endothelium and vascular integrity, and allows distribution of nutrients and oxygen. BM also plays a major role in pathologies including tumor angiogenesis [5].

We review here the unique molecular properties of the capillary BM, which are crucial to control plasticity of endothelial cells. BM indeed vary in composition in a temporal and tissue-specific manner [6]. BM composition and structure are modified in many ways to generate specialized and context-specific assemblies [7]. Its core components are laminins 411 and 511, collagen IV, perlecan and nidogen 1 and 2. The vascular BM also contains associated proteins including collagen XVIII, VI and VIII and fibronectin. In addition to the properties of each of these components, their scaffolding in the BM is a key process in vascular development and homeostasis. The capillary microenvironment also plays the role of a reservoir for many growth factors and proteins that regulate vascular biology. The complete vascular surroundings therefore orchestrate the capacity of vascular cells to sense and respond to both mechanical and chemical cues from the environment and is thus a key regulator of vascular homeostasis. The aim of the review is to give an overview of the role of BM components and scaffolding in vascular development and homeostasis. 


\section{Core components of the vascular basement membrane}

The two major components of BM are laminins and collagen IV. Both undergo auto-assembly into macromolecular sheets interconnected by nidogen and perlecan. Laminin network is first assembled through interaction with cell surface receptors and then triggers deposition of nidogen and perlecan, which both participate to cross-linking of the collagen IV network in order to generate the core of the BM.

\subsection{Laminin}

Laminins are a large family of high molecular weight glycoproteins. They consist in heterotrimers composed of disulfide-linked subunits, the $\alpha, \beta$ and $\gamma$ chains, and are named according to the compostion of the heterotrimer, i.e. laminin 411 is composed of $\alpha 4, \beta 1$ and $\gamma 1$. Laminins have a cross-shaped structure where the long arm of the cross $(80 \mathrm{~nm})$ is an $\alpha$-helical coiled-coil formed by all three chains, whereas the short arms $(35-50 \mathrm{~nm})$ are composed of one chain each [8] (Figure 1). At the C-terminal extremity of the long arm, the $\alpha$ chains contain five laminin G-like (LG) domains that include the major cell-adhesive sites. The homologous short arms are arranged in a unique globular structure, the laminin N-terminal (LN) domain, connected to tandem repeats of laminin type epidermal growth factor-like (LE) domains. The overall structure is interrupted by two to three internal globular domains [9].

Whereas expression of the $\beta$ and $\gamma$ chains is ubiquitous, the $\alpha$ chain is restricted to certain tissues and cell types, thus allowing tissue-specific distribution of laminins. In addition, their expression is also modulated during development and in pathological states [8]. They are found underlying the endothelium and surrounding pericytes in the capillary wall. The most abundant laminins in the vascular BM are composed of the $\alpha 4$ and $\alpha 5$ chains combined with laminin $\beta 1$ and $\gamma 1$ chains to form laminins 411 and 511 [10-13]. Laminin $\alpha 2$ is expressed during development (laminin 211) and also in the mature BM (laminin 221) [14] (Table 1).

Laminin interactions with cellular receptors, such as integrins via the globular domain at the C-terminus of its long arm, support assembly of other protein networks in the BM. Indeed, retention of laminin at the cell surface promotes further polymerization of the network, as demonstrated using in vitro planar lipid bilayers containing sulfated glycolipids [15]. The N-terminal short arms of the three chains mediate self-assembly of laminin polymers (Figure 1). Laminin network undergoes selfassembly at the endothelial cell surface and is considered to initiate BM deposition. The role of laminin scaffolding on vascular development and homeostasis will be further described in chapter 4.1.

\subsection{Collagen IV}

\subsubsection{Synthesis and secretion}

Whereas collagen IV is also a heterotrimer, its subunits share quite similar structure with one another. Six distinct collagen IV $\alpha$ chains (from $\alpha 1$ to $\alpha 6$ encoded by COL4A1 to COL4A6 genes, respectively) are expressed and assemble with a remarkable specificity to form only three distinct heterotrimers ( $\alpha 1 \alpha 1 \alpha 2, \alpha 3 \alpha 4 \alpha 5$ and $\alpha 5 \alpha 5 \alpha 6), \alpha 1 \alpha 1 \alpha 2$ being the most predominant in all tissues 
including vascular BM (Table 2). The $\alpha$ chains are approximatively $400 \mathrm{~nm}$ long and can be separated into three domains: a short $\mathrm{N}$-terminal $7 \mathrm{~S}$ domain, a long middle triple helical collagenous domain, and a C-terminal globular non-collagenous (NC1) domain (Figure 2).

The assembly of collagen IV trimers is initiated by interactions between the NC1 globular domains of three $\alpha$ chains that lead to formation of a heterotrimeric protomer. Both the 7S and NC1 domains are then responsible for the assembly of collagen IV networks [16]. Two collagen IV protomers associate via their C-terminal NC1 trimers and four protomers are cross-linked at the Nterminal 7S domain. In parallel, lateral associations between these assembled molecules form an elaborate supramolecular scaffold and allow formation of the complex mesh network of collagen IV. Unlike fibrillar collagens, the central collagenous domain of collagen IV is characterized by numerous (21 to 26 depending on the $\alpha$ chain) interruptions of the Gly-X-Y motifs that confer the structural flexibility responsible for its mesh-like network organization in the BM. In addition, the high level of covalent crosslinks provides stiffness to this structural scaffold.

Collagen IV secretion and supramolecular assembly into the BM require a variety of complex intracellular and extracellular molecular interactions. Among these, interactions with intracellular chaperones such as Hsp47 and the chaperone-binding Tango1 are required for proper collagen IV protomer stability and secretion. Hsp47 does not bind to unfolded or misfolded proteins but preferentially recognizes properly folded triple helices of fibril-forming procollagens and collagen IV protomers in the endoplasmic reticulum (ER). This protein may stabilize collagen IV protomers from the ER to the cis-Golgi [17] and is required for proper BM biosynthesis [18]. Moreover, osteonectin also known as secreted protein acidic and rich in cysteine (SPARC) or basement-membrane protein 40 (BM-40) has recently been proposed to act as an extracellular chaperone-like protein for collagen IV. It is proposed to ensure the proper deposition and assembly of collagen IV molecules in the BM, and to prevent premature collagen IV organization at sites of production, enabling diffusion and assembly to more distal sites [19].

\subsubsection{Assembly in the BM}

In all BMs, the collagen IV network is cross-linked to the laminin network through perlecan and nidogen. Synthesis, deposition and scaffolding of collagen IV networks by endothelial cells have been shown to be a central regulator of blood vessel formation and is mandatory for blood vessel survival and maturation in vivo ([20] and chapter 4.2 of the present review). Collagen IV networks display a highly oriented macromolecular organization in the BM. For long, the hypothesis has been that collagen IV form a horizontally organized network through its NC1 and 7S domains that serves as the main scaffold for the BM [21]. However, recent studies on $\alpha 3 \alpha 4 \alpha 5$ heterotrimers in kidney or retina $\mathrm{BM}$ have reported a polarized distribution for collagen IV trimers as the $\mathrm{N}$ - and C-terminaldomains are localized to opposite sides of the BM [22]. Indeed, the 7S domain is detected at the stromal side whereas the NC1 domains have been detected as primarily associated to the cell surface. Other recent studies also support this hypothesis [23], suggesting that collagen IV could be organized in such a way that the protein extends throughout the entire width of the vascular BM with the C-terminus pointing out towards the endothelium and the $\mathrm{N}$-terminus towards the interstitial ECM. This highly orientated distribution thus questions not only the horizontal positioning of collagen IV molecules proposed in the current BM model, but also the functional roles of the 
macromolecular organization of collagen IV. Besides, it has also been demonstrated that distribution of laminin is very similar to NC1 collagen IV at the cell-BM interface. These collagen IV and laminin networks are tightly connected by aggregated perlecan [24]. In addition to this specific orientation, the chains composing the collagen IV heterotrimers are also specific depending on their cellular expression. For example, in the kidney glomerular BM, collagen IV $\alpha 1 \alpha 1 \alpha 2$ protomers produced by the endothelial cells form a network closely juxtaposed to the endothelium, whereas the $\alpha 3 \alpha 4 \alpha 5$ protomers secreted only by podocytes are tightly attached to the $\alpha 1 \alpha 1 \alpha 2$ network [25]. These distinct compositions of collagen IV protomers may be fundamental to establish and maintain the $\mathrm{BM}$ architecture therefore suggesting that organization of the BM plays a critical role in its function, and especially in this example, in the filtration capacity of the kidney.

\subsubsection{Cross-linking}

In addition to disulfide crosslinks, collagen IV network assembly is catalyzed by specific crosslinking enzymes, including peroxidasin and lysyl oxidases (LOXs).

Peroxidasin has recently been identified as cross-linking collagen IV through formation of sulfilimine bonds between a methionine sulfur and a lysine nitrogen of the NC1 domains, thus stabilizing the hexameric structure of collagen IV [26] (Figure 2). Peroxidasin-deficient mice show reduced collagen IV sulfilimine crosslinks and reduced stiffness of the renal tubular BM, thus providing direct evidence for the contribution of collagen IV cross-linking to BM mechanical properties [27]. This however does not result in a vascular phenotype in these mice.

LOXs are secreted copper-containing amine oxidases that catalyze the oxidative deamination of lysines and hydroxylysines in collagens to form semi-aldehydes known as allysines. These highly reactive groups then undergo spontaneous reactions resulting in collagen cross-linking. LOX enzymes thus do not directly cross-link collagens but catalyze the last step required for its cross-linking [28]. They play important roles at different levels of the vascular system. Gene inactivation experiments have demonstrated that whereas LOXL1 only targets elastin [29], LOX cross-links both fibrillar collagen and elastin in the aorta [30,31], and does not affect collagen IV cross-linking or BM assembly [32]. The inactivation of LOX results in defects of aorta development leading to rupture and perinatal birth. Deletion of Loxl2 gene in mice promotes perinatal lethality with incomplete penetrance associated to congenital heart defects and distension of hepatic blood vessels [33]. We have shown that LOXL2-depletion in endothelial cells results in defects in collagen IV deposition and cross-linking in the ECM [34]. More recently, cross-linking of the 7S N-terminal domain by LOXL2 was demonstrated [35]. Besides, we demonstrated that LOXL2 regulates angiogenesis in vivo, as LOXL2 down-regulation inhibits formation of intersomitic vessels in zebrafish embryos, and in vitro, using 3 D culture models [34].

\subsection{Perlecan and nidogen}

Perlecan, a secreted heparan sulfate proteoglycan (HSPG), is another major component of the core endothelial BM. Perlecan has a very large multi-domain core protein (approximately 470 $\mathrm{kDa}$ ), carrying three long $\mathrm{N}$-terminal heparan sulfate (HS) side chains of $65 \mathrm{kDa}$ each. The core protein, composed of five distinct structural domains, is bound to the laminin network, whereas the HS are bound to the collagen IV network [24] most likely at its 7S and NC1 domains [8]. Perlecan has 
the potential to provide a bridge between laminin and the cell surface through its $\alpha$-DG-binding LG domains [36]. The N-terminal HS side chains also allow perlecan to sequester and present growth factors to their appropriate receptors (see chapter 5 ). This role is quite important for establishing growth factor gradients required for developmental processes and regulating angiogenesis (reviewed in [37]).

Perlecan can act as a regulator of cell adhesion, proliferation and growth factor signaling [38]. The C-terminal domain, responsible for oligomeric self-assembly and integrin-binding activity, is crucial for developmental and tumor angiogenesis. This domain, named endorepellin, can be processed by various proteases, and displays anti-angiogenic activities [39, 40]. In zebrafish embryo, knocking down perlecan expression using morpholinos leads to defects in sprouting of primary intersegmental vessels, showing the importance of perlecan in vascular morphogenesis. The phenotype is partially rescued by microinjection of human perlecan protein, or endorepellin [41]. Half of the perlecan-deficient mice die early in development, at E10.5, when expression of the Perlecan gene is normally initiated [42]. At E10-11, many perlecan-deficient embryos show signs of cardiac failure characterized by intrapericardial hemorrhages, weak heartbeats, or even cardiac arrest. Mutants that survive show abnormal BM formation.

Agrin is another secreted HSPG that interacts with core components of the BM. It directly binds the laminin $\gamma 1$ chain via its $\mathrm{N}$-terminal domain [8]. The agrin bridge has been shown to strengthen laminin anchorage both in vitro and in vivo $[43,44]$. In the BM, agrin was recently shown to have a polarized distribution with the C-terminus pointing to the podocyte or endothelial cell surface, and the $\mathrm{N}$-terminus to the center of the glomerular BM [25]. The functions of agrin are regulated by alternative splicing of its LG3 domain [45]. The non-neural splice variant of agrin is responsible for its contribution to BM formation and stability, whereas the neural splice variant plays an important role in the formation of neuromuscular junctions. Agrin might also play a role in the blood-brain-barrier as it accumulates in the BM of cerebral microvessels [46] and contributes to the localization of ß-catenin, VE-Cadherin and ZO-1 at the endothelial adherens junctions [47].

Two nidogen proteins, nidogen-1 and -2 (entactin- 1 and -2 , respectively) are encoded by two different genes but share the same structure. Like perlecan, nidogens act as linkers of the core components of BM. They contain binding sites in the $\mathrm{G} 3$ domain for the short arm of the $\gamma 1$ laminin subunit and in the $\mathrm{G} 2$ domain for collagen IV and perlecan [48-50]. Both isoforms are ubiquitous BM components. However, nidogen-1 is predominant in the vascular BM in adult. Only deletion of both nidogen genes results in perinatal lethality possibly due to cardiovascular and/or respiratory failure, whereas individual knockouts are viable and fertile [51]. Locally restricted bleeding within the heart wall has been reported in mutant embryos. This bleeding seems to be associated to leakage of the microvasculature and absence of capillary BM. Therefore, nidogens do not seem essential for BM formation but may play a role in maintenance of capillary integrity.

\section{Extracellular matrix proteins associated to the vascular basement membrane}

Besides these core components, many associated proteins also play a role in maintaining the BM functions and in connecting the BM to the interstitial ECM. We will present here collagens associated to the BM and fibronectin, which constitutes a functional bridge between the endothelial cell surface and the surrounding microenvironment. 


\subsection{Collagens}

\subsubsection{Collagen XVIII}

Collagen XVIII is a ubiquitous BM collagen, reaching high levels in the endothelial BM. It is a high molecular weight protein (approximately $300 \mathrm{kDa}$ ) that possesses structural properties of both collagen and proteoglycans, with several glycosaminoglycan chains consisting mainly in HS chains. Collagen XVIII is classified under the group of multiplexins due to the presence of 11 non-collagenous interruptions alternating with 10 collagenous repeats within the central triple helix, conferring high flexibility to the protein. Collagen XV, the other multiplexin collagen specific for BM, is mainly involved in cardiovascular development [52]. Homotrimerization of collagen XVIII is triggered by assembly of the NC1 domains. As collagen IV, collagen XVIII displays a very polarized orientation in epidermal and endothelial BMs, the C-terminal domain being orientated towards the cell surface, whereas the $\mathrm{N}$-terminus resides at the BM-interstitial ECM interface [53]. This polarization suggests an anchoring role for collagen XVIII between cells and interstitial ECM. Co-localization of the Cterminal domain of collagen XVIII with perlecan and laminin in the BM is consistent with such polarization [54]. Collagen XVIII binding to the BM could be mediated by HS chains [55]. Collagen XVIII-deficient mice show thickened epidermal BM, suggesting an important structural role for collagen XVIII in maintaining BM physical integrity [56].

Three different tissue-specific isoforms, with core proteins ranging from 135 to $178 \mathrm{kDa}$, that differ in their $\mathrm{N}$-terminal non-collagenous sequence, have been identified. The shortest variant is found in most vascular BMs. Collagen XVIII became a focus of interest when an $18 \mathrm{kDa}$ C-terminal tryptic peptide, named endostatin, turned out to have anti-angiogenic and tumor-suppressing activities [57]. In vitro and in vivo anti-angiogenic effects of endostatin have been further confirmed [53]. Several ocular abnormalities including abnormal outgrowth of retinal vessels [58] and reduced susceptibility to high oxygen-induced retinal neovascularization were reported in collagen XVIIIdeficient mice [59].

\subsubsection{Collagen VIII}

Collagen VIII was initially termed endothelial collagen due to its high expression in the endothelial BM [60]. Collagen VIII is a trimeric non-fibrillar short-chain collagen expressed as homotrimers of $\alpha 1$ or $\alpha 2$ chains of 74 and $67 \mathrm{kDa}$, respectively. They are very similar and share an identical domain structure consisting of a short non-collagenous domain 2 (NC2), followed by a collagen triple helix domain and a C-terminal non-collagenous domain 1 (NC1).

While the function of collagen VIII is uncertain, the importance of this collagen in the vasculature has been particularly reported in maintaining the smooth muscle cell phenotype. It may provide a substratum for a variety of cells and facilitate migration of endothelial cells in angiogenesis, smooth muscle cells in intimal invasion and myofibroblasts in fibrotic conditions [61]. Other studies suggest that the close association of collagen VIII to the BM may improve its resistance to compression, and that it would be synthesized during capillary sprouting [62]. 


\subsubsection{Collagen VI}

Collagen VI is ubiquitously expressed and has been studied in a wide range of tissues including the vessel wall. Though not considered as a BM associated collagen per se, collagen $\mathrm{VI}$ is a BM-anchoring protein with specific biosynthetic process and structural organization. Filaments of collagen VI are composed of heterotrimers of $\alpha$ chains ranging from approximately 100 to $350 \mathrm{kDa}$ encoded by six different genes (from COL6A1 to COL6A6). They mostly organize into a heterotrimer composed of $\alpha 1 \alpha 2 \alpha 3$. The $\alpha 4, \alpha 5$ and $\alpha 6$ chains share a structure similar to the $\alpha 3$ chain and have been proposed to replace the $\alpha 3$ chain under some pathological conditions [63]. Supra-molecular assembly of collagen $\mathrm{VI}$ is driven by a multi-step process and leads to the formation of a characteristic and distinctive network of beaded microfilaments in the ECM. However, in contrast to other types of collagens, collagen VI undergoes an intracellular assembly into large aggregates before being secreted [64]. The three $\alpha$ chains assemble to form a triple-helix monomer that joins into disulfide-bonded antiparallel dimers, which then align to form large tetramers also stabilized by disulfide bonds. These tetramers are finally secreted in the extracellular space and associate together through non-covalent bonds to form the beaded microfilaments [65]. Collagen VI forms an anchoring meshwork that connects the interstitial matrix to the vascular BM, thus bridging cells to the surrounding environment and organizing the three-dimensional tissue architecture of the vasculature through direct interaction with collagen IV [66]. Interactions with other fibrillar collagens, including collagen I, have also been reported [67]. Collagen VI and fibronectin have been shown to interact together $[66,68]$. Depletion of collagen VI leads to an increase in both fibronectin expression and extracellular deposition, which is then rearranged into long and parallel fibrils. Exogenous collagen $\mathrm{VI}$ restores the basal level of fibronectin deposition, suggesting that collagen $\mathrm{VI}$ is a regulator of fibronectin fibrillogenesis [69].

\subsection{Fibronectin}

\subsubsection{Expression and fibrillogenesis}

Fibronectin (FN) is a ubiquitously expressed BM-associated protein. In the vessel wall, it is incorporated between endothelial and perivascular cells. It is a dimeric glycoprotein of high molecular weight, composed of three types of structural repeats (I, II, III). The N-terminal part contains a self-assembly domain that allows for individual fibronectin dimers to assemble in a process termed fibrillogenesis, resulting in a three-dimensional network. Different isoforms of fibronectin are generated by alternative splicing: 1) the soluble form, or plasma form ( $p-F N)$ produced by hepatocytes that circulates at high concentration in blood, and 2) the cellular form (c$\mathrm{FN}$ ) produced in tissues, that contains additional domains called EDA and EDB, and is incorporated in the ECM [70]. Fibronectin plays a crucial role in cell adhesion, growth, migration, and differentiation. It is essential to wound healing, embryo development and blood vessel morphogenesis. Fibronectin is a unique ECM component because it is detected both close to the cell surface, strongly associated to the endothelial BM but also more distantly, associated to the interstitial ECM. Whereas in vitro experiments demonstrate that c-FN is required for autocrine activity on cell-cell and cell-ECM interactions [71] recent in vivo loss of function experiments proposed that $\mathrm{p}$-FN could play a critical role during vascular development [72].

\subsubsection{Assembly in the extracellular matrix}


Fibronectin fibrillogenesis is a non-spontaneous process, mediated by cells via integrin binding to the RGD motif. Fibronectin binding to integrins induces their clustering. These integrin clusters locally provide very high concentrations of fibronectin at the cell surface, which may promote fibronectin-fibronectin interactions and fibrillogenesis. Other matrix proteins have been involved in fibronectin fibrillogenesis such as ECM proteoglycans [73]. Transglutaminase-2 (TG2), a calcium-dependent enzyme, stabilizes the ECM through its cross-linking activity. Furthermore, TG2 interacts with $\beta 1$ integrin and fibronectin. This ternary complex promotes fibronectin deposition and pericellular network of fibrils [74].

Direct interaction of fibronectin with type IV collagen has been known for long [75]. A recent study further reported that fibronectin fibrillogenesis is required for type IV collagen deposition [76]. Disruption of fibronectin network affects type IV collagen and laminin deposition in the BM of human trabecular meshwork cells [77]. In a similar manner, interactions between type I collagen and fibronectin suggest that fibronectin acts as a scaffold that may participate to the alignment of collagen fibrils. Fibronectin fibers may thus organize and orient cells so that collagen fibers are aligned and parallel, thus constituting a functional bridge between the endothelial cell surface and the surrounding ECM.

\section{Basement membrane scaffolding and function in vascular development and homeostasis}

This chapter will focus on the functional role of BM core components in capillary formation and vascular homeostasis described in mouse models and human pathologies.

\subsection{Laminins}

Among the three main laminin isoforms expressed in vascular BMs, we will here focus on laminins 411 and 511 that are the two major isoforms found in vascular BMs. We will not review laminin $\alpha 2$, present in the mature vessels and vascular smooth muscle BMs [78] but predominantly expressed in striated muscles and peripheral nerves and for which the KO mouse models are reviewed in [79].

\subsubsection{Laminin 411}

Laminin $\alpha 4$ expression begins at E8.5 and is not restricted to a special type of vessel. The role of laminin $\alpha 4$ has been studied during vascularization of the mouse retina. It regulates tip and stalk cell number and vascular density by regulating the endothelial delta-like 4 (DII4)/Notch pathways [80]. Laminin $\alpha 4$ is mainly expressed at the growing vascular front in the postnatal retina, and its expression is mostly concentrated at the leading tip cells. It is hypothesized that laminin $\alpha 4$ could induce Dll4 expression specifically in tip cells through a $\beta 1$ integrin-mediated mechanism. The phenotype of the laminin $\alpha 4$ knockout mouse shows a central role for the laminin $\alpha 4$ chain in microvessel growth, resulting in bleeding and hemorrhages of capillaries, leaving large vessels unaffected [81]. The hemorrhages are associated with abnormalities of the BM, i.e. reduced deposition of collagen IV, nidogen, and laminin $\alpha 1$ chain. These defects in vascular BM are observed in newborn but not adult null mice [81], suggesting compensation at later stages. Consistent with this 
observation, laminin $\alpha 4$ knockout mice that survive beyond the perinatal period have a lifespan comparable to the wild-type controls. Mice lacking laminin $\alpha 4$ show excessive filopodia activity and tip cell formation in the retina. This phenotype is close to the phenotype observed when Notch is inhibited in vivo, leading to aberrant sprouting angiogenesis and branching [80].

\subsubsection{Laminin 511}

Laminin $\alpha 5$ is the other major laminin chain strongly expressed in the endothelial BM. Laminin $\alpha 5$ expression begins when the heart starts beating (E10) and blood circulation is initiated, mainly in arteries. It is expressed in the BM of microvessels at much later stages, and may be associated with maturation of the endothelium or its tissue/organ-specific characteristics [82, 83]. Laminin $\alpha 5$ is not expressed in fenestrated endothelium of endocrine glands and peritubular capillaries of the kidney [14] suggesting a correlation between absence of laminin $\alpha 5$ and fenestration formation. In postcapillary and larger venules, distribution of laminin $\alpha 5$ is patchy, resulting in BM regions containing only laminin $\alpha 4$ or both laminin $\alpha 4$ and $\alpha 5$ [14]. The exact role of this endothelial laminin in vascular homeostasis has not been fully reported. Deletion of laminin $\alpha 5$ in mouse models results in multiple defects and embryonic lethality at E10-E11 due to placental defects, failure of dorsal aorta closure and structural abnormalities and leakiness of the yolk sac vessels [84]. Kidney defects characterized by abnormal glomerular BM and glomerulogenesis are observed in these Lama5 null embryos [85].

Recent publications indicate that endothelial laminin $\alpha 5$ is essential to the shear stress response [86]. In vitro and in vivo analyses suggest that laminin $\alpha 5$ binding to $\beta 1$ integrin stabilizes VE-cadherin at adherens junctions, thus increasing the strength of cell-cell adhesion, which is essential to shear stress response and vessel permeability [86]. There is however at this point only little evidence that laminins may be involved in such mechanosensing functions. Other publications support the fact that the RGD-binding integrins, $\alpha 5 \beta 1$ or $\alpha v \beta 3$ could play a role in shear-induced intracellular signaling in cultured endothelial cells [87]. Moreover, using a conditional knockout mouse, it was demonstrated that loss of pericyte-produced laminin $\gamma 1$ is involved in the maintenance of the blood brain barrier integrity [88].

\subsection{Collagen IV}

Double deletion of Col4a1 and Col4a2 results in complete loss of collagen IV in the vascular BM and mouse embryo death at E10.5-11.5 [20]. Embryos display BM structural deficiency associated with dilated, fragile blood vessels and hemorrhages. Brain vascular beds display reduced capillary density and perturbed endothelial protrusions in the neural layers, whereas development of the large vessels is not affected by the deletion [20]. This demonstrates that collagen IV is not critically important for the formation of embryonic BM but is crucial for its structural integrity and function at later stages in development, especially upon mechanical demand after initiation of blood flow. In agreement with these results, we showed that down-regulating COLAA1 in endothelial cells affects capillary formation in a 3D angiogenesis model in fibrin gels [34].

Mutations in collagen IV are associated with defects in capillary formation and vessel integrity in human pathologies [89-91]. In the past decade, COL4A1 and COL4A2 mutations have 
been identified as a cause of multi-system disorder for which penetrance and severity of constituent phenotypes can greatly vary. COL4A1 mutations were found to cause porencephaly. This disease is characterized by cerebral cavities that communicate with the ventricles. Porencephaly is commonly associated with seizures, and mental retardation. It also causes pre- and perinatal hemorrhages, and recurrent intracerebral hemorrhages in young and old patients. The intracerebral hemorrhages can appear spontaneously or can be triggered by specific events. Porencephaly is often associated with systemic small-vessel disease, as mutations in COLAA1 compromises the BM and weakens the vessels [90, 92-94]. More than 100 mutations identified in patients were analyzed, showing that glycine substitutions within the triple helical domain are the most common type of mutations in patients. Glycine is often replaced by a charged amino acid. The position rather than the nature of the mutation is crucial for disease severity [95]. Other mutations responsible for hereditary angiopathy with nephropathy, aneurysms, and muscle cramps (HANAC) syndrom have been identified in the integrin binding region of the collagen domain (G498V, G519R and G528E). Patients present arteriolar tortuosity in the retina, brain arterial aneuryms and microvessel defects. The vascular BM is interrupted and thinner [91]. Mutations in COL4A1 and COL4A2 genes are also associated with systemic small vessel disease and various symptoms especially affecting the eyes, muscles, kidney and brain [96]. The mutations lead to structural instability of all BMs [97]. Perturbations of the matrisome of cerebral blood vessels is a possible proximate cause in familial small vessel disease [98].

A recent study reported the analysis of the BM in human retinal microaneurysms [99]. Interestingly, microaneurysms presented BM thickening associated with increased expression of the core BM proteins (collagen IV, laminin, perlecan and nidogen) along with ECM remodeling enzymes. Indeed, small microaneurysms expressed increased expression of cross-linking enzymes of the LOX family (LOXL2 and LOXL4), whereas large microaneurysms expressed more matrix-metalloprotease MMP9 and plasminogen activator inhibitor-1. Thickening of the BM by accumulation of collagen IV probably produced by recruited pericytes was thus considered as a compensatory mechanism that would strengthen the vascular wall in the early phase of microaneurysm development [99]. Besides, LOXL2 had already been reported as a susceptibility gene to intracranial aneurysms [100] and further exome sequencing analyses have identified mutations in this gene related to familial intracranial aneurysm [101]. These data confirm the hypothesis of an important role for BM cross-linking by LOXL2 in this pathology.

\subsection{Fibronectin}

Numerous studies showed that fibronectin and its receptors play a major role in embryogenesis and vascular development [102]. Deletion of the Fibronectin gene in mouse leads to embryo lethality at E8.5, with severe cardiovascular defects including heart malformations and aberrant distribution of blood vessels in the yolk sac [103]. During mouse retina vascularization, endothelial tip cells are guided by pre-existing fibronectin deposited by astrocytes but also synthesize and assemble fibronectin de novo [34], a crucial step in the angiogenic process [104]. Accordingly, in vitro studies have also demonstrated that growing capillaries deposit their own fibronectin [105] whose assembly regulates and is required for capillary morphogenesis [106].

Whereas many effects of fibronectin are mediated by interaction with its integrin receptors, 
fibronectin also regulates angiogenesis in an integrin-independent manner, as shown by mutating the heparin-binding domains (HEP-II and HEP-III). Several mutations were identified in patients suffering from glomerulopathy with excessive fibronectin deposition but also in patients with proteinuria, hypertension and massive glomerular deposits of the $\mathrm{p}-\mathrm{FN}$, leading to renal failure [107]. The HEP-II and -III domains play a major role in regulating fibronectin assembly into organized fibrils in the ECM, but also keeps p-FN in a compact soluble form thus preventing its deposition in the ECM. It was suggested that these mutations impair the control of the assembly of fibronectin into fibrils but also the balance between soluble and insoluble FN, leading to abnormal incorporation of the non-fibrillar p-FN. These mutants display lower binding to heparin but also to endothelial cells and podocytes. In endothelial cells, this impairs spreading and cytoskeleton organization [107].

\section{The extracellular matrix: a reservoir for growth factors and matricellular proteins}

Numerous growth factors, including VEGFs, IGFs, FGFs, TGF- $\beta$ s, and HGF, have been found to associate with ECM proteins or with HS chains and play a crucial role in vascular development and homeostasis. Some of them are necessary for sprouting angiogenesis, whereas others are tuning this process. We will here review the implication of VEGF and PDGF family of growth factors in vascular homeostasis.

\subsection{The VEGF family and its receptors}

Vascular endothelial growth factors (VEGFs) are crucial regulators of vasculogenesis and angiogenesis and are essential for vascular homeostasis. The VEGF family comprises several distinct proteins, we here focus on VEGF-A due to its main role in angiogenesis and vascular integrity as well as its predominant association with the vascular BM. Alternative splicing of the VEGF-A pre-mRNA produces several isoforms, each with different affinities for ECM and different biological activity. The predominant form, $\mathrm{VEGF}_{165}$, binds to the ECM and to the cell surface by its heparin binding sites. $\mathrm{VEGF}_{165}$ binds to the tyrosine kinase receptors VEGFR-1 and VEGFR-2 by diffusion or by presentation through co-receptors such as HSPGs. Binding causes dimerization of receptors, changes in the conformation, and phosphorylation of tyrosine residues that triggers activation of downstream signal transducers and signaling pathways that regulate angiogenesis [108].

ECM-associated HSPGs also bind to VEGF 165 and potentiate VEGFR-2 signaling [109]. VEGF ${ }_{165}$ signaling in endothelial cells is also fully supported by HS expressed in trans by adjacent perivascular smooth muscle cells [110]. Transactivation of VEGFR-2 leads to prolonged and enhanced signal transduction due to HS-dependent trapping of the active VEGFR-2 signaling complex and constitutes a crosstalk mechanism between adjacent cells. Regulation of VEGF 165 interaction with HSPG by other HSPG-binding proteins can also modulate VEGFR-2 signaling. Indeed, inactivation of tg2 in mouse resulted in increased vascularization in the retina together as a result of increased phosphorylation of VEGFR-2 at Tyr951 and its downstream targets Src and Akt [105].

Fibronectin also regulates angiogenesis through interactions with growth factors, including TGF- $\beta$ [111] and VEGF [104]. Indeed, fibronectin binds to VEGF and thus regulates migration and proliferation of endothelial cells. In mouse retina, fibronectin binding to $\mathrm{VEGF}_{165}$ secreted by astrocytes promotes the directional migration of tip cells. The role of fibronectin as a "VEGF-A organizer" and as a migration ligand for endothelial cells during sprouting angiogenesis has been well 
described [104]. Astrocytes are the major source of cellular fibronectin during retinal angiogenesis and its deletion reduced endothelial migration during vascular plexus morphogenesis. This effect could be recapitulated by selectively inhibiting VEGF-A binding to fibronectin via injection of blocking peptides. A similar phenotype was reported upon double deletion of fibronectin and HSPGs in the retina, suggesting that both components of the ECM synergize to bind to VEGF-A and support migration and orientation of tip cells. Altogether, these data indicate that fibronectin participates to the vascular branching pattern in the retina via binding to VEGF-A.

\subsection{The PDGF family and its receptors}

Platelet-derived growth factor (PDGF) is a potent mitogen for cells of mesenchymal origin, including fibroblasts, smooth muscle cells and glial cells. It regulates cell growth and division. PDGF plays a significant role in angiogenesis. In both mouse and human, the PDGF signaling network consists of four ligands (PDGF-A, PDGF-B, PDGF-C and PDGF-D) and two tyrosine kinase receptors (PDGFR- $\alpha$ and PDGFR- $\beta$ ). Secreted PDGF acts both in an autocrine and paracrine manner. It regulates angiogenesis through pericyte recruitment and stabilization of neovessels. PDGF-B, released from endothelial tip cells at the migration front, recruits mural cells that express PDGFR- $\beta$ and especially pericytes [3]. Knockouts of Pdgfb and Pdgfrb in mouse lead to similar phenotypes of perinatal death due to vascular dysfunction caused by mural cell deficiency [112], leading to vascular leakage and abnormal junctions $[113,114]$. These defects induced a compensatory mechanism of up-regulation of VEGF-A, which in turn promotes further vascular leakage and hemorrhage [115].

PDGF-B binds to heparin and HSPGs in the ECM via its C-terminal retention motif that limits the range of action of PDGF-B necessary for adhesion of pericytes to the vessel wall. In mice, deletion of this motif perturbs pericyte coverage in microvessels thus showing that PDGF-B-oriented presentation at the endothelial cell surface is crucial for pericyte recruitment [116]. HSPGs actually constitute a PDGF storage compartment at the cell surface and in the ECM, and these interactions regulate spatial distribution and bioavailability of PDGF at sites of pericyte recruitment such as angiogenic sprouts.

\subsection{Matricellular proteins}

\subsubsection{Angiopoietins}

Angiopoietins are part of a family of vascular growth factors that play a role in embryonic and postnatal angiogenesis, as well as in stabilization and maturation of blood vessels. Angiopoietins are involved in regulating vascular permeability, vasodilation, and vasoconstriction. Among them, Angiopoietin-1 (Ang-1) interacts with the ECM, whereas Ang-2 is more diffusible [117]. These interactions provide different local concentrations and are thought to account in part for the differences in the biological effect of the angiopoietins. Indeed, matrix-bound Ang-1 induces cell adhesion, motility and Tie 2 activation in cell-matrix contacts, eventually translocated to the trailing edge in migrating endothelial cells. In contrast, Ang1-induced Tie2 translocation to cell-cell contacts triggers the formation of homotypic Tie2-Tie2 trans-associated complexes in contacting cells. Distinct signalling proteins are therefore activated by Tie2 in the cell-matrix and cell-cell contacts, where Ang2 inhibits Ang1-induced Tie2 activation [118]. Also, Ang-3 is tethered on the cell surface via HSPGs [119]. As for angiopoietin like-proteins, angiopoietin like-4 (ANGPTL4), a key regulator of 
lipoprotein lipase activity thereby impacting processing and distribution of triglycerides and cholesterol, is also secreted by endothelial cells in hypoxia [120] and interacts with HSPGs [121]. It regulates developmental and pathological retinal vascularization by limiting cell adhesion, cell junction organization, pericyte coverage [122]. ANGPTL4 also plays a role in vessel integrity, limiting vascular permeability in ischemic pathologies [122-124].

\subsection{2. $\mathrm{CCN}$ proteins}

Other ECM-associated integrin- and heparin-binding proteins belong to the CCN family and are functionally involved in the development of the vascular system. $\mathrm{CCN}$ is an acronym that refers to the initials of the first three family members namely cysteine-rich 61 (CYR61) for CCN1, connective tissue growth factor (CTGF) for CCN2 and nephroblastoma overexpressed (NOV) for CCN3. There are three other members of this family [125]. They all share structural characteristics but are all functionally different. By far, CCN1 and CCN2 display more important roles in vascular development and diseases [126]. They provide the functional bridge between structural macromolecules and growth factors, cytokines, proteases, and other related proteins [127]. Structurally, they are arranged as multimodular molecules composed of four cysteine-rich motifs.

CCN1 and CCN2 are critical regulators of endothelial cell differentiation, mural cell recruitment and $\mathrm{BM}$ formation during embryonic vascular development. Once secreted, CCN1 controls adhesion, proliferation and survival through interaction with integrins. CCN1 signaling often requires HSPGs as co-receptors. Mice lacking CCN1 phenocopied $\alpha 4$ and $\beta V$ integrin-deficiency, leading to similar vascular defects [128]. CCN1 can also bind ECM proteins such as fibronectin or vitronectin and thus potentiates their activation of $\alpha \mathrm{V}$ integrins [129]. As for CCN1, the role of CCN2 is context-dependent and is determined by the bioavailability of membrane receptors and/or presence of interacting molecules in the microenvironment. Through direct binding to $\alpha \mathrm{V} \beta 3$ integrin, CCN2 promotes endothelial cell adhesion, migration, and tube formation [130, 131]. CCN2 also regulates gene expression of growth factors and ECM components [132, 133].

\section{Concluding remarks}

This review describes the specific composition of the vascular BM and highlights the functional roles of this spatially-orientated structure (Figure 3 ). In addition to its proteolytic regulation, increasing number of studies demonstrate that regulation of the assembly of the ECM and its components is a decisive process in vascular morphogenesis. Some ECM remodeling enzymes play a key role, by allowing scaffolding and organization of protein components.

The ECM is a reservoir for growth factors that influence angiogenesis by controlling specific signaling pathways. Regulation of their bioavailability directly impacts on vascular morphogenesis and homeostasis. These combined processes are key events of the dynamic regulation that leads to a specifically and functionally orientated structure, as discussed earlier for the collagen IV and XVIII polarization in the vascular BM.

The ECM is a crucial regulator of the cell microenvironment and tissue organization. Cells assemble soluble proteins into insoluble fibrils embedded in a hydrophilic polysaccharide-based ECM with unique mechanical properties and chemical composition thus generating the cues that will 
regulate cell-cell interactions and morphogenesis. Cellular traction forces are indeed considered as effectors activated by mechanosensing in order to regulate matrix remodeling [134]. Cells thus both sense and influence ECM mechanics to maintain tissue homeostasis. Works developed over the last 15 years have demonstrated the crucial role of ECM-mediated mechanotransduction as a major regulator of morphogenetic processes including angiogenesis. Fluid shear stress has been considered as the main source of mechanical signals regulating vascular function for long and is still under deep investigation $[135,136]$. It is now also established that substrate mechanical properties can also influence sprouting and vascular network formation. Endothelial cells establish perfused vessels in any tissue but cartilage, thus encountering a huge diversity of microenvironments. Such context pushes forward the role of the vascular BM as the stable structural feature that will allow vascular interactions with- and functions in- any tissue. The mechanisms that stand behind these relationships however still require deep investigation. Overall, a better understanding of the mechanical and structural properties of the vascular BM and interstitial ECM undoubtedly opens new perspectives to control physiological and pathological angiogenesis and vascular homeostasis.

Acknowledgements

The authors wish to thank France Maloumian for designing the figures.

Fundings

This work was partially supported by Fondation pour la Recherche Médicale and INSERM.

The authors declare no competing financial interest. 
Table 1. Laminin isoforms in vascular BM

\begin{tabular}{|c|c|c|c|c|}
\hline Chains & Expression & Heterotrimers & Vascular specificity & References \\
\hline$\alpha 4$ & endothelial and mural cells & \multirow{3}{*}{411} & \multirow{3}{*}{ all blood vessels } & \multirow{3}{*}{ [14] } \\
\hline$\beta 1$ & ubiquitous & & & \\
\hline$\gamma$ & ubiquitous & & & \\
\hline$\alpha 5$ & endothelial and mural cells & \multirow{3}{*}{511} & \multirow{3}{*}{ capillaries } & \multirow{3}{*}{ [14] } \\
\hline$\beta 1$ & ubiquitous & & & \\
\hline$\gamma 1$ & ubiquitous & & & \\
\hline$\alpha 2$ & mural cells & \multirow{3}{*}{211} & \multirow{3}{*}{$\begin{array}{c}\text { blood brain barrier } \\
\text { vessels }\end{array}$} & \multirow{3}{*}[3,137]{} \\
\hline$\beta 1$ & ubiquitous & & & \\
\hline$\gamma$ & ubiquitous & & & \\
\hline$\alpha 2$ & mural cells & \multirow{3}{*}{221} & \multirow{3}{*}{$\begin{array}{l}\text { mature blood } \\
\text { vessels }\end{array}$} & \multirow{3}{*}[14,138]{} \\
\hline$\beta 2$ & widely expressed & & & \\
\hline$\gamma 1$ & ubiquitous & & & \\
\hline
\end{tabular}

Table 2. Collagen IV heterotrimers in BMs

\begin{tabular}{cccc}
\hline Heterotrimers & Expression & Vascular orientation & References \\
\hline \hline$\alpha 1 \alpha 1 \alpha 2$ & all vascular BMs & $\begin{array}{c}\text { closely juxtaposed to the } \\
\text { endothelium }\end{array}$ & {$[16,25]$} \\
$\alpha 3 \alpha 4 \alpha 5$ & glomerular, eye, lung, testis & distant from the endothelium & {$[25]$} \\
$\alpha 5 \alpha 5 \alpha 6$ & kMs & - & {$[16]$} \\
\hline
\end{tabular}




\section{References}

[1] Lohler J, Timpl R, Jaenisch R. Embryonic lethal mutation in mouse collagen I gene causes rupture of blood vessels and is associated with erythropoietic and mesenchymal cell death. Cell 1984;38:597-607.

[2] Davis GE, Senger DR. Endothelial extracellular matrix: biosynthesis, remodeling, and functions during vascular morphogenesis and neovessel stabilization. Circ Res 2005;97:1093107.

[3] Armulik A, Genove G, Betsholtz C. Pericytes: developmental, physiological, and pathological perspectives, problems, and promises. Dev Cell 2011;21:193-215.

[4] Stratman AN, Davis GE. Endothelial cell-pericyte interactions stimulate basement membrane matrix assembly: influence on vascular tube remodeling, maturation, and stabilization. Microsc Microanal 2012;18:68-80.

[5] Kalluri R. Basement membranes: structure, assembly and role in tumour angiogenesis. Nat Rev Cancer 2003;3:422-33.

[6] Hynes RO, Naba A. Overview of the matrisome--an inventory of extracellular matrix constituents and functions. Cold Spring Harb Perspect Biol 2012;4:a004903.

[7] Uechi G, Sun Z, Schreiber EM, Halfter W, Balasubramani M. Proteomic View of Basement Membranes from Human Retinal Blood Vessels, Inner Limiting Membranes, and Lens Capsules. J Proteome Res 2014.

[8] Hohenester E, Yurchenco PD. Laminins in basement membrane assembly. Cell Adh Migr 2013;7:56-63.

[9] Yurchenco PD. Integrating Activities of Laminins that Drive Basement Membrane Assembly and Function. Curr Top Membr 2015;76:1-30.

[10] Frieser M, Nockel H, Pausch F, Roder C, Hahn A, Deutzmann R, et al. Cloning of the mouse laminin alpha 4 cDNA. Expression in a subset of endothelium. Eur J Biochem 1997;246:727-35.

[11] livanainen A, Sainio K, Sariola H, Tryggvason K. Primary structure and expression of a novel human laminin alpha 4 chain. FEBS Lett 1995;365:183-8.

[12] Sorokin L, Girg W, Gopfert T, Hallmann R, Deutzmann R. Expression of novel 400-kDa laminin chains by mouse and bovine endothelial cells. Eur J Biochem 1994;223:603-10. [13] Sorokin LM, Pausch F, Frieser M, Kroger S, Ohage E, Deutzmann R. Developmental regulation of the laminin alpha5 chain suggests a role in epithelial and endothelial cell maturation. Dev Biol 1997;189:285-300.

[14] Yousif LF, Di Russo J, Sorokin L. Laminin isoforms in endothelial and perivascular basement membranes. Cell Adh Migr 2013;7:101-10.

[15] Kalb E, Engel J. Binding and calcium-induced aggregation of laminin onto lipid bilayers. J Biol Chem 1991;266:19047-52.

[16] Khoshnoodi J, Pedchenko V, Hudson BG. Mammalian collagen IV. Microsc Res Tech 2008;71:357-70.

[17] Koide T, Takahara Y, Asada S, Nagata K. Xaa-Arg-Gly triplets in the collagen triple helix are dominant binding sites for the molecular chaperone HSP47. J Biol Chem 2002;277:617882.

[18] Nagai N, Hosokawa M, Itohara S, Adachi E, Matsushita T, Hosokawa N, et al. Embryonic lethality of molecular chaperone hsp47 knockout mice is associated with defects in collagen biosynthesis. J Cell Biol 2000;150:1499-506. 
[19] Chioran A, Duncan S, Catalano A, Brown TJ, Ringuette MJ. Collagen IV trafficking: The inside-out and beyond story. Dev Biol 2017;431:124-33.

[20] Poschl E, Schlotzer-Schrehardt U, Brachvogel B, Saito K, Ninomiya Y, Mayer U. Collagen IV is essential for basement membrane stability but dispensable for initiation of its assembly during early development. Development 2004;131:1619-28.

[21] Timpl R, Wiedemann H, van Delden V, Furthmayr H, Kuhn K. A network model for the organization of type IV collagen molecules in basement membranes. Eur J Biochem 1981;120:203-11.

[22] Halfter W, Monnier C, Muller D, Oertle P, Uechi G, Balasubramani M, et al. The bifunctional organization of human basement membranes. PLoS One 2013;8:e67660.

[23] Jayadev R, Sherwood DR. Basement membranes. Curr Biol 2017;27:R207-R11.

[24] Behrens DT, Villone D, Koch M, Brunner G, Sorokin L, Robenek H, et al. The epidermal basement membrane is a composite of separate laminin- or collagen IV-containing networks connected by aggregated perlecan, but not by nidogens. J Biol Chem 2012;287:18700-9. [25] Suleiman H, Zhang L, Roth R, Heuser JE, Miner JH, Shaw AS, et al. Nanoscale protein architecture of the kidney glomerular basement membrane. Elife 2013;2:e01149.

[26] Bhave G, Cummings CF, Vanacore RM, Kumagai-Cresse C, Ero-Tolliver IA, Rafi M, et al. Peroxidasin forms sulfilimine chemical bonds using hypohalous acids in tissue genesis. Nat Chem Biol 2012;8:784-90.

[27] Bhave G, Colon S, Ferrell N. The sulfilimine cross-link of collagen IV contributes to kidney tubular basement membrane stiffness. Am J Physiol Renal Physiol 2017;313:F596-F602. [28] Trackman PC. Enzymatic and non-enzymatic functions of the lysyl oxidase family in bone. Matrix Biol 2016;52-54:7-18.

[29] Liu X, Zhao Y, Gao J, Pawlyk B, Starcher B, Spencer JA, et al. Elastic fiber homeostasis requires lysyl oxidase-like 1 protein. Nat Genet 2004;36:178-82.

[30] Hornstra IK, Birge S, Starcher B, Bailey AJ, Mecham RP, Shapiro SD. Lysyl oxidase is required for vascular and diaphragmatic development in mice. J Biol Chem 2003;278:1438793.

[31] Maki JM, Rasanen J, Tikkanen H, Sormunen R, Makikallio K, Kivirikko KI, et al. Inactivation of the lysyl oxidase gene Lox leads to aortic aneurysms, cardiovascular dysfunction, and perinatal death in mice. Circulation 2002;106:2503-9.

[32] Maki JM, Sormunen R, Lippo S, Kaarteenaho-Wiik R, Soininen R, Myllyharju J. Lysyl oxidase is essential for normal development and function of the respiratory system and for the integrity of elastic and collagen fibers in various tissues. Am J Pathol 2005;167:927-36. [33] Martin A, Salvador F, Moreno-Bueno G, Floristan A, Ruiz-Herguido C, Cuevas EP, et al. Lysyl oxidase-like 2 represses Notch1 expression in the skin to promote squamous cell carcinoma progression. EMBO J 2015;34:1090-109.

[34] Bignon M, Pichol-Thievend C, Hardouin J, Malbouyres M, Brechot N, Nasciutti L, et al. Lysyl oxidase-like protein-2 regulates sprouting angiogenesis and type IV collagen assembly in the endothelial basement membrane. Blood 2011;118:3979-89.

[35] Anazco C, Lopez-Jimenez AJ, Rafi M, Vega-Montoto L, Zhang MZ, Hudson BG, et al. Lysyl Oxidase-like-2 Cross-links Collagen IV of Glomerular Basement Membrane. J Biol Chem 2016;291:25999-6012.

[36] Hohenester E, Tisi D, Talts JF, Timpl R. The crystal structure of a laminin G-like module reveals the molecular basis of alpha-dystroglycan binding to laminins, perlecan, and agrin. Mol Cell 1999;4:783-92. 
[37] Gubbiotti MA, Neill T, lozzo RV. A current view of perlecan in physiology and pathology: A mosaic of functions. Matrix Biol 2017;57-58:285-98.

[38] Lord MS, Chuang CY, Melrose J, Davies MJ, lozzo RV, Whitelock JM. The role of vascularderived perlecan in modulating cell adhesion, proliferation and growth factor signaling. Matrix Biol 2014;35:112-22.

[39] Douglass S, Goyal A, lozzo RV. The role of perlecan and endorepellin in the control of tumor angiogenesis and endothelial cell autophagy. Connect Tissue Res 2015;56:381-91.

[40] Poluzzi C, lozzo RV, Schaefer L. Endostatin and endorepellin: A common route of action for similar angiostatic cancer avengers. Adv Drug Deliv Rev 2016;97:156-73.

[41] Zoeller JJ, McQuillan A, Whitelock J, Ho SY, lozzo RV. A central function for perlecan in skeletal muscle and cardiovascular development. J Cell Biol 2008;181:381-94.

[42] Costell M, Gustafsson E, Aszodi A, Morgelin M, Bloch W, Hunziker E, et al. Perlecan maintains the integrity of cartilage and some basement membranes. J Cell Biol 1999;147:1109-22.

[43] McKee KK, Capizzi S, Yurchenco PD. Scaffold-forming and Adhesive Contributions of Synthetic Laminin-binding Proteins to Basement Membrane Assembly. J Biol Chem 2009;284:8984-94.

[44] Moll J, Barzaghi P, Lin S, Bezakova G, Lochmuller H, Engvall E, et al. An agrin minigene rescues dystrophic symptoms in a mouse model for congenital muscular dystrophy. Nature 2001;413:302-7.

[45] Bezakova G, Ruegg MA. New insights into the roles of agrin. Nat Rev Mol Cell Biol 2003;4:295-308.

[46] Barber AJ, Lieth E. Agrin accumulates in the brain microvascular basal lamina during development of the blood-brain barrier. Dev Dyn 1997;208:62-74.

[47] Steiner E, Enzmann GU, Lyck R, Lin S, Ruegg MA, Kroger S, et al. The heparan sulfate proteoglycan agrin contributes to barrier properties of mouse brain endothelial cells by stabilizing adherens junctions. Cell Tissue Res 2014;358:465-79.

[48] Fox JW, Mayer U, Nischt R, Aumailley M, Reinhardt D, Wiedemann H, et al.

Recombinant nidogen consists of three globular domains and mediates binding of laminin to collagen type IV. EMBO J 1991;10:3137-46.

[49] Hopf M, Gohring W, Ries A, Timpl R, Hohenester E. Crystal structure and mutational analysis of a perlecan-binding fragment of nidogen-1. Nat Struct Biol 2001;8:634-40.

[50] Mayer U, Nischt R, Poschl E, Mann K, Fukuda K, Gerl M, et al. A single EGF-like motif of laminin is responsible for high affinity nidogen binding. EMBO J 1993;12:1879-85.

[51] Bader BL, Smyth N, Nedbal S, Miosge N, Baranowsky A, Mokkapati S, et al. Compound genetic ablation of nidogen 1 and 2 causes basement membrane defects and perinatal lethality in mice. Mol Cell Biol 2005;25:6846-56.

[52] Rasi K, Piuhola J, Czabanka M, Sormunen R, Ilves M, Leskinen $\mathrm{H}$, et al. Collagen XV is necessary for modeling of the extracellular matrix and its deficiency predisposes to cardiomyopathy. Circ Res 2010;107:1241-52.

[53] Seppinen L, Pihlajaniemi T. The multiple functions of collagen XVIII in development and disease. Matrix Biol 2011;30:83-92.

[54] Javaherian K, Park SY, PickI WF, LaMontagne KR, Sjin RT, Gillies S, et al. Laminin modulates morphogenic properties of the collagen XVIII endostatin domain. J Biol Chem 2002;277:45211-8.

[55] Dong S, Cole GJ, Halfter W. Expression of collagen XVIII and localization of its glycosaminoglycan attachment sites. J Biol Chem 2003;278:1700-7. 
[56] Utriainen A, Sormunen R, Kettunen M, Carvalhaes LS, Sajanti E, Eklund L, et al. Structurally altered basement membranes and hydrocephalus in a type XVIII collagen deficient mouse line. Hum Mol Genet 2004;13:2089-99.

[57] O'Reilly MS, Boehm T, Shing Y, Fukai N, Vasios G, Lane WS, et al. Endostatin: an endogenous inhibitor of angiogenesis and tumor growth. Cell 1997;88:277-85.

[58] Marneros AG, Keene DR, Hansen U, Fukai N, Moulton K, Goletz PL, et al. Collagen $\mathrm{XVIII/endostatin} \mathrm{is} \mathrm{essential} \mathrm{for} \mathrm{vision} \mathrm{and} \mathrm{retinal} \mathrm{pigment} \mathrm{epithelial} \mathrm{function.} \mathrm{EMBO} \mathrm{J}$ 2004;23:89-99.

[59] Hurskainen M, Eklund L, Hagg PO, Fruttiger M, Sormunen R, llves M, et al. Abnormal maturation of the retinal vasculature in type XVIII collagen/endostatin deficient mice and changes in retinal glial cells due to lack of collagen types XV and XVIII. FASEB J 2005;19:15646.

[60] Sage H, Trueb B, Bornstein P. Biosynthetic and structural properties of endothelial cell type VIII collagen. J Biol Chem 1983;258:13391-401.

[61] Hou G, Mulholland D, Gronska MA, Bendeck MP. Type VIII collagen stimulates smooth muscle cell migration and matrix metalloproteinase synthesis after arterial injury. Am J Pathol 2000;156:467-76.

[62] Sage H, Iruela-Arispe ML. Type VIII collagen in murine development. Association with capillary formation in vitro. Ann N Y Acad Sci 1990;580:17-31.

[63] Gara SK, Grumati P, Urciuolo A, Bonaldo P, Kobbe B, Koch M, et al. Three novel collagen VI chains with high homology to the alpha3 chain. J Biol Chem 2008;283:10658-70.

[64] Colombatti A, Mucignat MT, Bonaldo P. Secretion and matrix assembly of recombinant type VI collagen. J Biol Chem 1995;270:13105-11.

[65] Baldock C, Sherratt MJ, Shuttleworth CA, Kielty CM. The supramolecular organization of collagen VI microfibrils. J Mol Biol 2003;330:297-307.

[66] Kuo HJ, Maslen CL, Keene DR, Glanville RW. Type VI collagen anchors endothelial basement membranes by interacting with type IV collagen. J Biol Chem 1997;272:26522-9.

[67] Bonaldo P, Russo V, Bucciotti F, Doliana R, Colombatti A. Structural and functional features of the alpha 3 chain indicate a bridging role for chicken collagen $\mathrm{VI}$ in connective tissues. Biochemistry 1990;29:1245-54.

[68] Tillet E, Wiedemann H, Golbik R, Pan TC, Zhang RZ, Mann K, et al. Recombinant expression and structural and binding properties of alpha $1(\mathrm{VI})$ and alpha $2(\mathrm{VI})$ chains of human collagen type VI. Eur J Biochem 1994;221:177-85.

[69] Groulx JF, Gagne D, Benoit YD, Martel D, Basora N, Beaulieu JF. Collagen VI is a basement membrane component that regulates epithelial cell-fibronectin interactions. Matrix Biol 2011;30:195-206.

[70] Astrof S, Hynes RO. Fibronectins in vascular morphogenesis. Angiogenesis 2009;12:16575.

[71] Cseh B, Fernandez-Sauze S, Grall D, Schaub S, Doma E, Van Obberghen-Schilling E. Autocrine fibronectin directs matrix assembly and crosstalk between cell-matrix and cell-cell adhesion in vascular endothelial cells. J Cell Sci 2010;123:3989-99.

[72] Kumra H, Sabatier L, Hassan A, Sakai T, Mosher DF, Brinckmann J, et al. Roles of fibronectin isoforms in neonatal vascular development and matrix integrity. PLoS Biol 2018;16:e2004812.

[73] Chung CY, Erickson HP. Glycosaminoglycans modulate fibronectin matrix assembly and are essential for matrix incorporation of tenascin-C. J Cell Sci 1997;110 ( Pt 12):1413-9. 
[74] Akimov SS, Belkin AM. Cell-surface transglutaminase promotes fibronectin assembly via interaction with the gelatin-binding domain of fibronectin: a role in TGFbeta-dependent matrix deposition. J Cell Sci 2001;114:2989-3000.

[75] Aumailley M, Timpl R. Attachment of cells to basement membrane collagen type IV. J Cell Biol 1986;103:1569-75.

[76] Miller CG, Pozzi A, Zent R, Schwarzbauer JE. Effects of high glucose on integrin activity and fibronectin matrix assembly by mesangial cells. Mol Biol Cell 2014;25:2342-50.

[77] Filla MS, Dimeo KD, Tong T, Peters DM. Disruption of fibronectin matrix affects type IV collagen, fibrillin and laminin deposition into extracellular matrix of human trabecular meshwork (HTM) cells. Exp Eye Res 2017;165:7-19.

[78] Rauch U, Saxena A, Lorkowski S, Rauterberg J, Bjorkbacka H, Durbeej M, et al. Laminin isoforms in atherosclerotic arteries from mice and man. Histol Histopathol 2011;26:711-24. [79] Yao Y. Laminin: loss-of-function studies. Cell Mol Life Sci 2017;74:1095-115.

[80] Stenzel D, Franco CA, Estrach S, Mettouchi A, Sauvaget D, Rosewell I, et al. Endothelial basement membrane limits tip cell formation by inducing DIl4/Notch signalling in vivo.

EMBO Rep 2011;12:1135-43.

[81] Thyboll J, Kortesmaa J, Cao R, Soininen R, Wang L, livanainen A, et al. Deletion of the laminin alpha4 chain leads to impaired microvessel maturation. Mol Cell Biol 2002;22:1194202.

[82] Hallmann R, Horn N, Selg M, Wendler O, Pausch F, Sorokin LM. Expression and function of laminins in the embryonic and mature vasculature. Physiol Rev 2005;85:979-1000.

[83] Sorokin LM, Pausch F, Durbeej M, Ekblom P. Differential expression of five laminin alpha (1-5) chains in developing and adult mouse kidney. Dev Dyn 1997;210:446-62.

[84] Coles EG, Gammill LS, Miner JH, Bronner-Fraser M. Abnormalities in neural crest cell migration in laminin alpha5 mutant mice. Dev Biol 2006;289:218-28.

[85] Miner JH, Li C. Defective glomerulogenesis in the absence of laminin alpha5 demonstrates a developmental role for the kidney glomerular basement membrane. Dev Biol 2000;217:278-89.

[86] Di Russo J, Luik AL, Yousif L, Budny S, Oberleithner H, Hofschroer V, et al. Endothelial basement membrane laminin 511 is essential for shear stress response. EMBO J 2017;36:183-201.

[87] Tzima E, del Pozo MA, Shattil SJ, Chien S, Schwartz MA. Activation of integrins in endothelial cells by fluid shear stress mediates Rho-dependent cytoskeletal alignment. EMBO J 2001;20:4639-47.

[88] Gautam J, Zhang X, Yao Y. The role of pericytic laminin in blood brain barrier integrity maintenance. Sci Rep 2016;6:36450.

[89] Gould DB, Phalan FC, Breedveld GJ, van Mil SE, Smith RS, Schimenti JC, et al. Mutations in Col4a1 cause perinatal cerebral hemorrhage and porencephaly. Science 2005;308:1167-

71.

[90] Gould DB, Phalan FC, van Mil SE, Sundberg JP, Vahedi K, Massin P, et al. Role of COL4A1 in small-vessel disease and hemorrhagic stroke. N Engl J Med 2006;354:1489-96.

[91] Plaisier E, Gribouval O, Alamowitch S, Mougenot B, Prost C, Verpont MC, et al. COL4A1 mutations and hereditary angiopathy, nephropathy, aneurysms, and muscle cramps. N Engl J Med 2007;357:2687-95.

[92] Federico A, Di Donato I, Bianchi S, Di Palma C, Taglia I, Dotti MT. Hereditary cerebral small vessel diseases: a review. J Neurol Sci 2012;322:25-30. 
[93] Kuo DS, Labelle-Dumais C, Gould DB. COL4A1 and COL4A2 mutations and disease: insights into pathogenic mechanisms and potential therapeutic targets. Hum Mol Genet 2012;21:R97-110.

[94] Vahedi K, Alamowitch S. Clinical spectrum of type IV collagen (COL4A1) mutations: a novel genetic multisystem disease. Curr Opin Neurol 2011;24:63-8.

[95] Jeanne M, Gould DB. Genotype-phenotype correlations in pathology caused by collagen type IV alpha 1 and 2 mutations. Matrix Biol 2017;57-58:29-44.

[96] Favor J, Gloeckner CJ, Janik D, Klempt M, Neuhauser-Klaus A, Pretsch W, et al. Type IV procollagen missense mutations associated with defects of the eye, vascular stability, the brain, kidney function and embryonic or postnatal viability in the mouse, Mus musculus: an extension of the Col4a1 allelic series and the identification of the first two Col4a2 mutant alleles. Genetics 2007;175:725-36.

[97] Van Agtmael T, Schlotzer-Schrehardt U, McKie L, Brownstein DG, Lee AW, Cross SH, et al. Dominant mutations of Col4a1 result in basement membrane defects which lead to anterior segment dysgenesis and glomerulopathy. Hum Mol Genet 2005;14:3161-8. [98] Joutel A, Haddad I, Ratelade J, Nelson MT. Perturbations of the cerebrovascular matrisome: A convergent mechanism in small vessel disease of the brain? J Cereb Blood Flow Metab 2016;36:143-57.

[99] Lopez-Luppo M, Nacher V, Ramos D, Catita J, Navarro M, Carretero A, et al. Blood Vessel Basement Membrane Alterations in Human Retinal Microaneurysms During Aging. Invest Ophthalmol Vis Sci 2017;58:1116-31.

[100] Akagawa H, Narita A, Yamada H, Tajima A, Krischek B, Kasuya H, et al. Systematic screening of lysyl oxidase-like (LOXL) family genes demonstrates that LOXL2 is a susceptibility gene to intracranial aneurysms. Hum Genet 2007;121:377-87.

[101] Wu Y, Li Z, Shi Y, Chen L, Tan H, Wang Z, et al. Exome Sequencing Identifies LOXL2 Mutation as a Cause of Familial Intracranial Aneurysm. World Neurosurg 2018;109:e812-e8. [102] Van Obberghen-Schilling E, Tucker RP, Saupe F, Gasser I, Cseh B, Orend G. Fibronectin and tenascin-C: accomplices in vascular morphogenesis during development and tumor growth. Int J Dev Biol 2011;55:511-25.

[103] George EL, Georges-Labouesse EN, Patel-King RS, Rayburn H, Hynes RO. Defects in mesoderm, neural tube and vascular development in mouse embryos lacking fibronectin. Development 1993;119:1079-91.

[104] Stenzel D, Lundkvist A, Sauvaget D, Busse M, Graupera M, van der Flier A, et al. Integrin-dependent and -independent functions of astrocytic fibronectin in retinal angiogenesis. Development 2011;138:4451-63.

[105] Beckouche N, Bignon M, Lelarge V, Mathivet T, Pichol-Thievend C, Berndt S, et al. The interaction of heparan sulfate proteoglycans with endothelial transglutaminase-2 limits VEGF165-induced angiogenesis. Sci Signal 2015;8:ra70.

[106] Zhou X, Rowe RG, Hiraoka N, George JP, Wirtz D, Mosher DF, et al. Fibronectin fibrillogenesis regulates three-dimensional neovessel formation. Genes Dev 2008;22:123143.

[107] Castelletti F, Donadelli R, Banterla F, Hildebrandt F, Zipfel PF, Bresin E, et al. Mutations in FN1 cause glomerulopathy with fibronectin deposits. Proc Natl Acad Sci U S A 2008;105:2538-43.

[108] Karaman S, Leppanen VM, Alitalo K. Vascular endothelial growth factor signaling in development and disease. Development 2018;145. 
[109] Cecchi F, Pajalunga D, Fowler CA, Uren A, Rabe DC, Peruzzi B, et al. Targeted disruption of heparan sulfate interaction with hepatocyte and vascular endothelial growth factors blocks normal and oncogenic signaling. Cancer Cell 2012;22:250-62.

[110] Jakobsson L, Kreuger J, Holmborn K, Lundin L, Eriksson I, Kjellen L, et al. Heparan sulfate in trans potentiates VEGFR-mediated angiogenesis. Dev Cell 2006;10:625-34.

[111] Fontana L, Chen Y, Prijatelj P, Sakai T, Fassler R, Sakai LY, et al. Fibronectin is required for integrin alphavbeta6-mediated activation of latent TGF-beta complexes containing LTBP-

1. FASEB J 2005;19:1798-808.

[112] Lindahl P, Johansson BR, Leveen P, Betsholtz C. Pericyte loss and microaneurysm formation in PDGF-B-deficient mice. Science 1997;277:242-5.

[113] Leveen P, Pekny M, Gebre-Medhin S, Swolin B, Larsson E, Betsholtz C. Mice deficient for PDGF B show renal, cardiovascular, and hematological abnormalities. Genes Dev 1994;8:1875-87.

[114] Soriano P. Abnormal kidney development and hematological disorders in PDGF betareceptor mutant mice. Genes Dev 1994;8:1888-96.

[115] Hellstrom M, Gerhardt H, Kalen M, Li X, Eriksson U, Wolburg H, et al. Lack of pericytes leads to endothelial hyperplasia and abnormal vascular morphogenesis. J Cell Biol 2001;153:543-53.

[116] Lindblom P, Gerhardt H, Liebner S, Abramsson A, Enge M, Hellstrom M, et al. Endothelial PDGF-B retention is required for proper investment of pericytes in the microvessel wall. Genes Dev 2003;17:1835-40.

[117] Xu Y, Yu Q. Angiopoietin-1, unlike angiopoietin-2, is incorporated into the extracellular matrix via its linker peptide region. J Biol Chem 2001;276:34990-8.

[118] Saharinen P, Eklund L, Miettinen J, Wirkkala R, Anisimov A, Winderlich M, et al.

Angiopoietins assemble distinct Tie2 signalling complexes in endothelial cell-cell and cellmatrix contacts. Nat Cell Biol 2008;10:527-37.

[119] Xu Y, Liu YJ, Yu Q. Angiopoietin-3 is tethered on the cell surface via heparan sulfate proteoglycans. J Biol Chem 2004;279:41179-88.

[120] Le Jan S, Amy C, Cazes A, Monnot C, Lamande N, Favier J, et al. Angiopoietin-like 4 is a proangiogenic factor produced during ischemia and in conventional renal cell carcinoma. Am J Pathol 2003;162:1521-8.

[121] Chomel C, Cazes A, Faye C, Bignon M, Gomez E, Ardidie-Robouant C, et al. Interaction of the coiled-coil domain with glycosaminoglycans protects angiopoietin-like 4 from proteolysis and regulates its antiangiogenic activity. FASEB J 2009;23:940-9.

[122] Perdiguero EG, Galaup A, Durand M, Teillon J, Philippe J, Valenzuela DM, et al. Alteration of developmental and pathological retinal angiogenesis in angpt|4-deficient mice. J Biol Chem 2011;286:36841-51.

[123] Galaup A, Gomez E, Souktani R, Durand M, Cazes A, Monnot C, et al. Protection against myocardial infarction and no-reflow through preservation of vascular integrity by angiopoietin-like 4. Circulation 2012;125:140-9.

[124] Gomez Perdiguero E, Liabotis-Fontugne A, Durand M, Faye C, Ricard-Blum S, Simonutti $M$, et al. ANGPTL4-alphavbeta3 interaction counteracts hypoxia-induced vascular permeability by modulating Src signalling downstream of vascular endothelial growth factor receptor 2. J Pathol 2016;240:461-71.

[125] Brigstock DR, Goldschmeding R, Katsube KI, Lam SC, Lau LF, Lyons K, et al. Proposal for a unified CCN nomenclature. Mol Pathol 2003;56:127-8. 
[126] Leask A, Abraham DJ. All in the CCN family: essential matricellular signaling modulators emerge from the bunker. J Cell Sci 2006;119:4803-10.

[127] Chaqour B. Molecular control of vascular development by the matricellular proteins CCN1 (Cyr61) and CCN2 (CTGF). Trends Dev Biol 2013;7:59-72.

[128] Bader BL, Rayburn H, Crowley D, Hynes RO. Extensive vasculogenesis, angiogenesis, and organogenesis precede lethality in mice lacking all alpha v integrins. Cell 1998;95:50719.

[129] Jim Leu SJ, Sung JS, Huang ML, Chen MY, Tsai TW. A novel anti-CCN1 monoclonal antibody suppresses Rac-dependent cytoskeletal reorganization and migratory activities in breast cancer cells. Biochem Biophys Res Commun 2013;434:885-91.

[130] Dean RA, Butler GS, Hamma-Kourbali Y, Delbe J, Brigstock DR, Courty J, et al. Identification of candidate angiogenic inhibitors processed by matrix metalloproteinase 2 (MMP-2) in cell-based proteomic screens: disruption of vascular endothelial growth factor (VEGF)/heparin affin regulatory peptide (pleiotrophin) and VEGF/Connective tissue growth factor angiogenic inhibitory complexes by MMP-2 proteolysis. Mol Cell Biol 2007;27:845465.

[131] Schober JM, Chen N, Grzeszkiewicz TM, Jovanovic I, Emeson EE, Ugarova TP, et al. Identification of integrin alpha(M)beta(2) as an adhesion receptor on peripheral blood monocytes for Cyr61 (CCN1) and connective tissue growth factor (CCN2): immediate-early gene products expressed in atherosclerotic lesions. Blood 2002;99:4457-65.

[132] James LR, Le C, Doherty H, Kim HS, Maeda N. Connective tissue growth factor (CTGF) expression modulates response to high glucose. PLoS One 2013;8:e70441.

[133] Tsoutsman T, Wang X, Garchow K, Riser B, Twigg S, Semsarian C. CCN2 plays a key role in extracellular matrix gene expression in severe hypertrophic cardiomyopathy and heart failure. J Mol Cell Cardiol 2013;62:164-78.

[134] Boldock L, Wittkowske C, Perrault CM. Microfluidic traction force microscopy to study mechanotransduction in angiogenesis. Microcirculation 2017;24.

[135] Gebala V, Collins R, Geudens I, Phng LK, Gerhardt H. Blood flow drives lumen formation by inverse membrane blebbing during angiogenesis in vivo. Nat Cell Biol 2016;18:443-50.

[136] Nakajima H, Yamamoto K, Agarwala S, Terai K, Fukui H, Fukuhara S, et al. FlowDependent Endothelial YAP Regulation Contributes to Vessel Maintenance. Dev Cell 2017;40:523-36 e6.

[137] Menezes MJ, McClenahan FK, Leiton CV, Aranmolate A, Shan X, Colognato H. The extracellular matrix protein laminin alpha2 regulates the maturation and function of the blood-brain barrier. J Neurosci 2014;34:15260-80.

[138] Glukhova M, Koteliansky V, Fondacci C, Marotte F, Rappaport L. Laminin variants and integrin laminin receptors in developing and adult human smooth muscle. Dev Biol 1993;157:437-47. 


\section{Figure legends}

Figure 1. Organization of laminins in the vascular basement membrane

The laminin network is constitued by the assembly of the $\alpha, \beta$ and $\gamma$ chains heterotrimer where the C-terminal long arms are orientated towards the cell surface and the $\mathrm{N}$-terminal short arms towards the collagen IV scaffold. The main interacting ECM components are indicated.

\section{Figure 2. Organization of collagen IV in the vascular basement membrane}

The collagen IV mesh network is constitued by scaffolding of the $\alpha$ chain heterotrimers. The NC1 domains cross-linked by the peroxidasin enzyme are orientated towards the laminin network. The 7S domains crosslinked after deamination of lysines by LOXL2 are orientated towards the interstitial ECM. 7S and $\mathrm{NCl}$ crosslinks are indicated in red. The main interacting ECM components are indicated.

Figure 3. Polarized basement membrane in capillary wall

The laminin network interacts with the cell surface directly through the integrins or indirectly through agrin and perlecan. The collagen scaffold interacts with the laminin network through perlecan and nidogen. 7S and $\mathrm{NCl}$ crosslinks are indicated in red. Fibronectin is present on the cell surface and intertitial sides of the basement membrane. 
Towards vascular BM

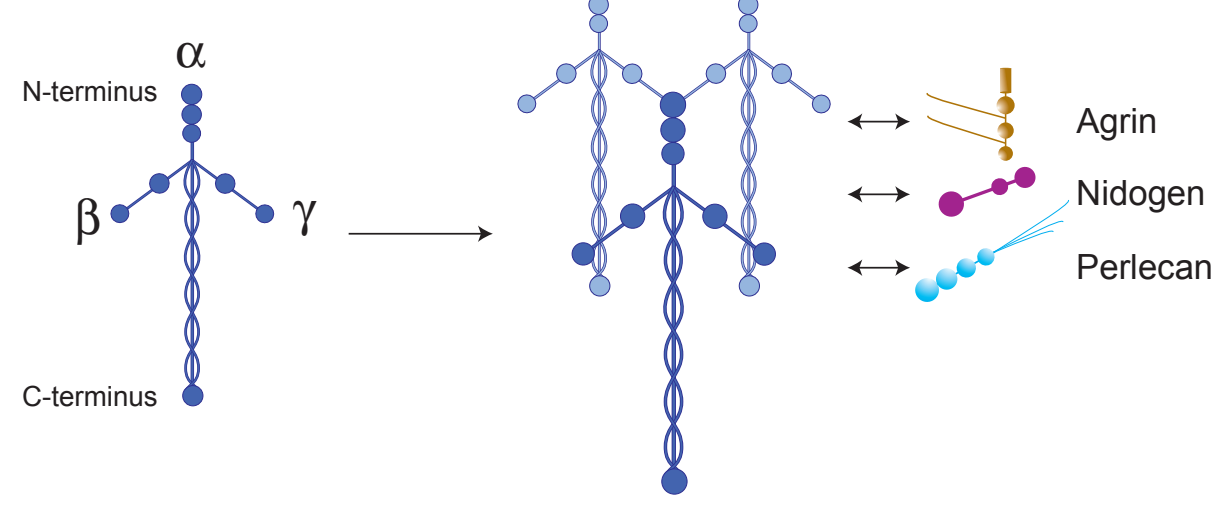

Towards endothelial cell surface 
Towards interstitial ECM

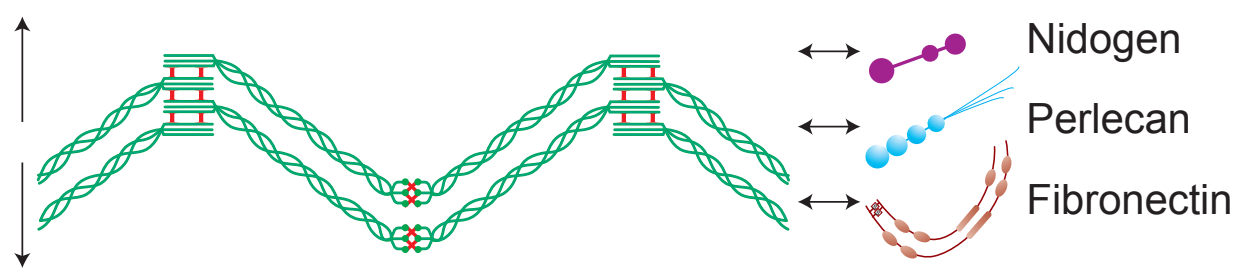

Towards vascular BM

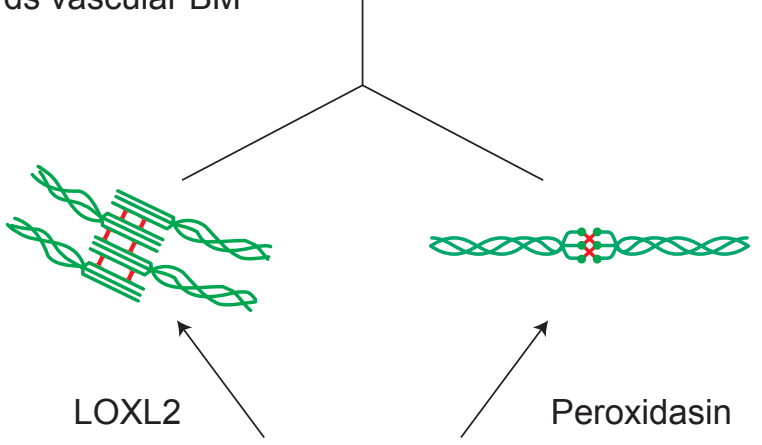

"esesosest:
7S domain
$\mathrm{N}$-terminus
$\mathrm{NCl}$ domain
C-terminus 


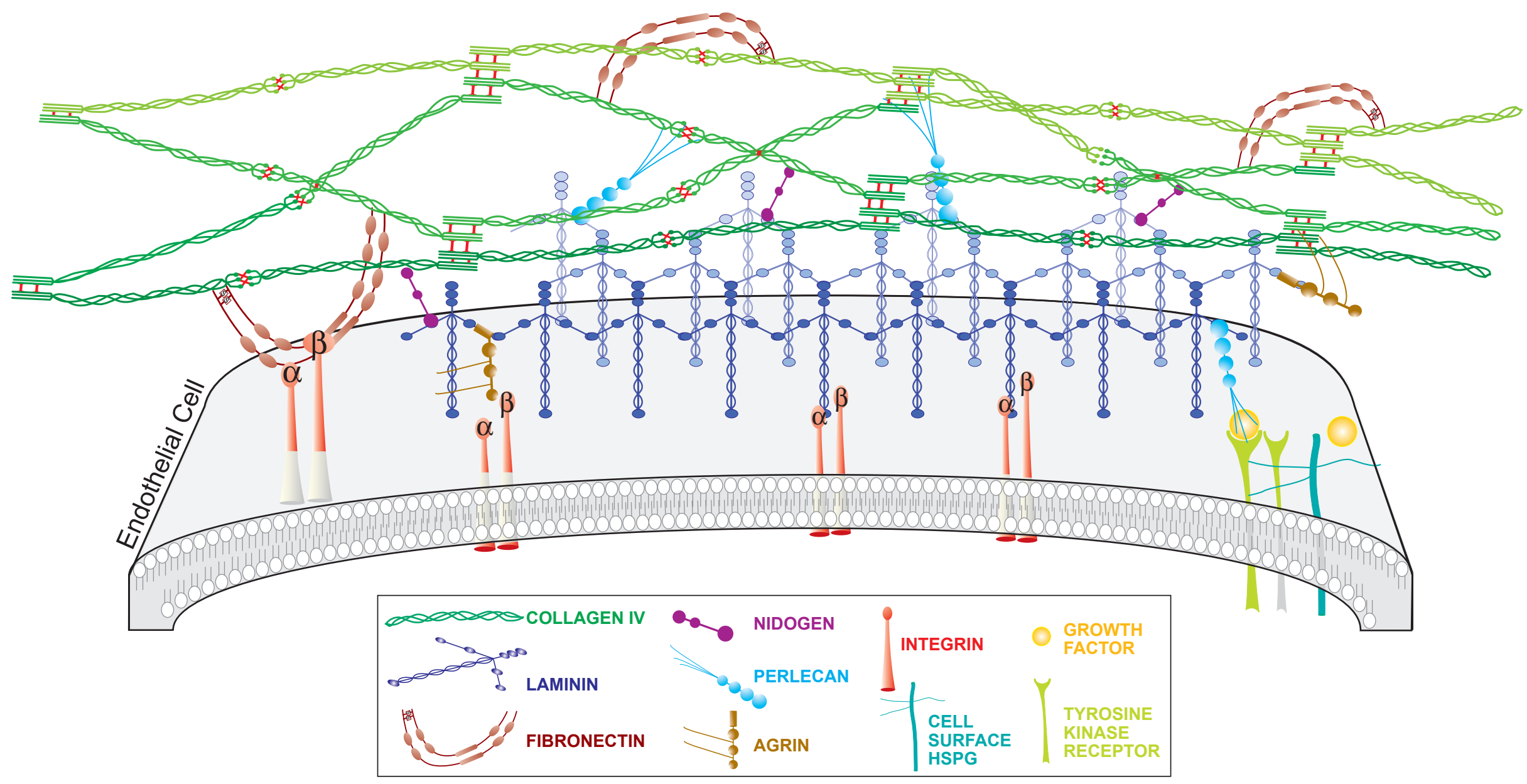

